\title{
0 "trust" anglo-americano e o "fideicomiso" latino-americano $(*)$
}

\author{
Waldemar Ferreira \\ Professor Emérito da Faculdade de Direito \\ da Universidade de São Paulo
}

\section{A substituição de herdeiros no direito lusitano}

Dispondo sôbre a substitựção de herdeiros, as Ordenações Filipinas de Portugal, no livro IV, título 87, houveram por bem conceituá-la. "Substituição é instituição de herdeiro feita pelo testador em segundo grau. E' pode ser uma de cinco, que em Direito se chamam vulgar, recíproca, pupilar, exemplar, compendiosa; as quais o Direito introduziu, para que os testadores tivessem mais fàcilmente quem aceitasse suas heranças".

Esta última forma de substituição de herdeiro, no $\S$ 12 do mesmo título se disse ser "a que um testador faz ao herdeiro, que instituiu, quando quer que êle falecer. $\mathrm{E}$ chama-se assim, porque debaixo de um compêndio de palavras contém em si muitas substituições de diferente natureza; a forma em que se faz, é esta: Instituo por meu herdeiro a Pedro; e quando êle falecer, ou depois de sua morte, ou por sua morte seja herdeiro Paulo"

(*) Dos Estudios Juridicos en Homenaje al Profesor Leopoldo Melo, da "Asociación Argentina de Derecho Comparado", Distribuidora Exclusiva Tipografica Argentina S. A., Buenos Aires, 1956, págs. 79 a 94 .

Fazendo apreciação dêsse livro em Jurisprudencia Argentina, de Buenos Aires, ano XX, de 31 de outubro de 1957, $\mathrm{n}^{\circ}$ 6.912, o Pro- 
Este dispositivo não figurava nas Ordenações Manoelinas, nem nas Ordenações Afonsinas. Tão pouco se deparava nas antigas leis portuguêsas. Transplantou-se, e melhor é dizê-lo por palavras de CoElHo Da RocHa, "quase fielmente copiado do Direito Romano do título do Digesto de vulgari et pupillari substitutione. Melo, atribuindo o favor, de que por êste direito gozavam as substituições, à sabida máxima dos romanos ignominiosum esse sacra

fessor HÉctor CÁmARA, da Faculdade de Direito e Ciências Sociais da Universidade Nacional de Córdova, assim se manifestou sôbre o estudo acima transcrito:

"Un insigne jurisconsulto, el Dr. Waldemar Martins Ferreira, trata $O$ trust angloamericano e o fideicomiso latinoamericano, tema que contemporáneamente ha ocupado la atención de la doctrina de nuestro continente, "lo que en parte tiene sus raíces en el aumento creciente de las relaciones entre dichos países y los Estados Unidos de Norte América, respondiendo fundamentalmente al deseo de dar al derecho privado nacional la flexibilidad necesaria para que permita alcanzar fines de imposible o difícil realización dentro de los esquemas tradicionales", al sentir de Goldschmidt. (1)

Comienza reseñando la sustitución fideicomisaria en el derecho lusitano, las leyes de Alfonso el Sabio, el C. C. chileno y sus antecedentes romanos como en el derecho alemán; se detiene en. Freitas, marcando su influencia sobre el C. C. argentino, donde es receptado en el campo de los derechos reales - dominio fiduciario -; empero, cabe apuntar que esa reglamentación es extraña al "trust angloamericano", ya que tal dominio tiene su origen en una trasferencia, aunque interna, realizada a favor del adquirente, mientras que la trasferencia de bienes resultante del negocio fiduciario de origen romano o del trust angloamericano opera en razón de intereses que, total o parcialmente, son ajenos al adquirente' (2).

En el código civil del Brasil menciona el art. 1733, autorizando al testador para instituir herederos o legatarios mediante fideicomisos, imponiendo a uno de ellos -el gravado o fiduciario- trasmitir al fideicomisario la herencia o legado después de su muerte, a cierto tiempo, o bajo cierta condición. Recuerda como nota his-

(1) Goldschmidt, Roserto, La Ley de los Fideicomisos de 1957, p. 5, Caracas, 1957.

(2) GoldschmidT, ob. cit., p. 8. 
privata vel domestica perire; e atendendo ao princípio dominante da legislação josefina, de que deviam antes favorecer-se as sucessões legítimas, não hesitou em escrever no L. 3, tit. 55, $\S 55$, nota: "e republica esse videbatur, ut

tórica los trabajos parlamentarios, donde hubo discrepancia entre la Comisión del Senado y de Diputados.

Cita también el art. 692, C. C. italiano vigente, que introdujo la sustitución fideicomisaria, rompiendo la hostilidad del legislador.

Estima que el contrato de derecho privado con el cual mayor afinidad presenta es la "comisión" a igual que entre nosotros, agregamos; tocante la naturaleza del trust, en la controversia entre quienes sostienen el desdoblamiento del dominio entre dos titulares y aquellos que propugnan que el cestui que trust no ostenta el dominio sino un derecho personal sobre el trustee, se inclina por la primera posición.

Se refiere brevemente al trasplante del trust en las legislaciones americanas, aludiendo en primer lugar a la ley argentina de debentures donde en verdad no tiene aplicación la institución angloamericana así como en otros países en especial, en el régimen bancario; sin embargo, omite el C. Com. de Honduras arts. 1033 a 1069, como la reciente ley venezolana del 17 de agosto de 1956, inspirada en el proyecto del Dr. Roberto Goldschmidt (3).

Luego de puntualizar la opinión siempre valiosa de CarvalHo DE Mendonça sobre los negocios fiduciarios y una sentencia de la Corte de Apelaciones del Distrito Federal, concluye que en la vida económica de aquel país se practican múltiples contratos similares al trust, no sintiéndose la necesidad de regularlos porque se solucionan echando mano de la comisión o del mandato.

La presente producción, prevalentemente de carácter objetivo, resulta de alto interés por lo novedoso del tema en dicho derecho como en el argentino donaje son contados los estudios (4) y las muchas sugerencias que provoca; sobre todo por la futura incrementación de las relaciones interamericanas."

(3) En descargo del autor, creemos que por su fecha no pudo tener tiempo para consultar esta ley.

(4) En el país la única obra que conocemos es la publicada por Goldschmidt y PH. J. EDER, "El fideicomiso" (Trust) en ét derecho comparado (especialmente americano), Bs. As., 1954. 
-substitutionum usus speciali lege proscriberetur". Nós, que hoje não somos tão austeros, ainda que não respeitemos a razão da Ord. - para que os testadores tivessem mais fàcilmente quem aceitasse suas heranças - contudo en"tendemos que as suas disposições a êste respeito são dignas de censura" (1).

Consolidando o direito português vigente no Brasil, "Teixeira de Freitas, no art. 1052 da Consolidação das Leis Civis, concretizou a substituição compendiosa em poucas palavras: "há substituição compendiosa quando o testador designa o herdeiro, que deve substituir ao herdeiro instituído, se êste vier a falecer"

Explicou o jurista exímio, em nota, que "esta substituição chama-se compendiosa, porque compreende a substituição vulgar e a substituição fideicomissária; de modo "qủe não há substituição compendiosa sem que seja fideicomissária, mas a substituição pode ser fideicomissária sem que seja compendiosa. Assim acontece se o testador dá substituto ao herdeiro instituído, quando êster falecer depois de ter aceitado a herança; e não para o caso de não querer, ou de não poder o herdeiro instituído aceitar a herança".

A essa substituição, e outro não é o testemunho de Melo Freire, se chamou simplesmente - fideicomisso; mas dela se usava mais por costume do que por lei, porquanto apenas se fazia menção dela nos antigos e novos códigos - nas Sete Partidas, moribus magis quam legibus.

Houve-se desde então como fiduciário ou gravado 0 herdeiro ou legatāio que recebia os bens hereditários transmissiveis, por sua morte, ou a prazo certo, ao fideicomissário, ou substituto, que recolhia a herança ou legado.

(1) M. A. Coelho DA Rocha, Instituições do Direito Civil Português, Rio de Janeiro, 1907, t. II, pág. 246, § 713. 


\section{A substituição fideicomissária nas Sete Partidas}

O asserto de Coelho da Rocha quanto ao transplantio dos dispositivos atinentes à substituição de herdeiros, consignada nas Ordenações Filipinas, ter-se feito, quase por cópia, do Digesto, se aplicaria às Sete Partidas com maior justeza.

Na lei $1 .^{a}$ do título $\mathrm{V}$ da Partida VI se atribuiu aos testadores poder para establecer otros herederos substituidos á los primeros, para el caso de que estos mueran, ó no cumplan la condicion y voluntad de aquellos.

Se cinco foram as espécies de substituição das Ordenações Filipinas, em seis se cifraram as das Sete Partidas. Son, nestas se estabeleceu, son seis las especies de substitucion: vulgar se llama la hecha en favor de alguno para el caso de que otro no quiera, ó no pueda ser heredero; pupilar es la que únicamente se hace al varon menor de 14 años, ó mujer menor de 12; y ejemplar es llamada la institucion hecha á semejanza de la del menor; la cual pueden hacer los padres y abuelos en sus descendientes locos y desmemoriados, estableciéndoles herederos para el caso de morir en la locura. Compendiosa substitucion se dice la concebida en breves palabras: brevilocua ó recíproca la hecha en pocas palabras comprensiva de cuatro substituciones, dos vulgares, y dos pupilares; otra se llama fideicomisaria: y de cada una de ellas se dirá en las siguientes leyes.

Desta lei, deve-se ressaltar a décima quarta. E a concernente à instituição do fideicomisso.

"Substitucion fideicomisaria es el establecimiento de heredero puesto en fé de alguno, para que dé la herencia á otro; como si el testador ruegue ó mande á su instituido, que tenga la herencia tanto tiempo, y despues la entregue á otro; lo cual puede hacer todo hombre á cualquiera del 
pueblo, que no se halle prohibido por las leyes: tal heredero fideicomisario debe dar la herencia al otro, sacando de ella para sí la cuarta parte llamada trebelliànica; y no queriendo recibir la herencia, á entregarla despues de recibida, puede ser apremiado por el juez".

Nesse dispositivo se abeberou o legislador chileno recolhendo em seu código o fideicomisso sucessório.

Definiu, no art. 1164, a substituição fideicomissária: es aquella en que se llama a un fideicomisario, que en el evento de una condicion se hace dueño absoluto de lo que otra persona poseía en propiedad fiduciaria.

Não ficou nisso o texto; mas acrescentou reger-se a substituição fideicomissária pelas regras da propriedade fiduciária, que instituiu.

Entrou então o Código Civil chileno na matéria dominial, prevendo os vários modos restritivos do domínio: $1^{\circ}$, por haver de passar a outra pessoa em virtude de uma comissão: 2. ${ }^{\circ}$, pelo gravâme de usufruto, uso ou habitação, a que alguma pessoa tenha direito em coisas pertencentes a outra; $3 .^{\circ}$, pelas servidões.

E acrescentou:

“733. Se llama propiedad fiduciaria la que está suSete r grrouámen de pasar a otra persona, por el hecho de verificarse una condicion.

La constitucion de la propiedad fiduciaria se llama fideicomiso.

Este nombre se da tambien a la cosa constituida en propiedad fiduciaria.

La traslacion de la propiedad a la persona en cuyo favor se ha constituido el fideicomiso, se llama restitucion"

Tomada essa posição, verdadeiramente marcante, o Código disciplinou pormenorizadamente a matéria, que tanto deveria repercutir, como aconteceu, nos outros países americanos de fala espanhola. 


\section{A atitude de Teixeira de Freitas e sua influência nos labores de Velez Sarsfield}

Elaborando o Esbôço do Código Civil brasileiro, em 1866, Teixeira de Freitas, no livro terceiro - o dos direitos reais, em título especial coordenou a matéria do domínio, direito de propriedade sôbre coisas certas, direito real, perpétuo ou temporário, duma só pessoa sôbre coisa própria, móvel, com todos os direitos sôbre sua substância e utilidade, ou sòmente sôbre sua substância, ou sòmente sôbre sua substância com alguns sôbre sua utilidade.

Dêsse conceito sobressaiu, dum lado, o domínio perfeito, direito real perpétuo duma só pessoa sôbre coisa própria, móvel ou imóvel, com todos os direitos sôbre sua substância e utilidade; e, de outro, o domínio imperfeito, direito real, resolúvel, ou fidu'ciário, de uma só pessoa sôbre uma coisa própria, móvel ou imóvel, ou o reservado pelo dono de uma coisa, que aliena sòmente seu domínio útil. O domínio fiduciário, em têrmos tais concebido, constituiria o fideicomisso singular, resultante da substituição direta ou substituição fideicomissária, mercê da doação com a cláusula de fazer-se com o encargo de restituir o donatário a terceiro os bens doados, cumprida a condição preestabelecida, ao depois do vencimento do prazo estipulado.

Essa substituição, outorgada pela doação, se regularia, em tudo quanto aplicavel, pelo que se dispusesse a respeito da substituição dos herdeiros e legatários, proibidas as doações fideicomissárias nos mesmos casos em que fôssem vedados os outros fideicomissos.

A interrupção do Esbôco, por motivos sobejamente conhecidos, quais, principalmente, o de haver TeIxeIra DE Freitas, nessa altura de seu trabalho, chegado à conclusão 
de que deveria rumar para a unificação do direito privado, não permitiu que a matéria do fideicomisso, no capítulo do direito sucessório, ganhasse o desenlace adequado.

Não obstou isso a que o trabalho de Teixeira de Freitas influisse, ainda nesse ponto, no de Velez Sarsfield, que seguiu as pégadas do genial jurisconsulto brasileiro, articulando, no título VII - o do domínio imperfeito, do Código Civil argentino, êstes preceitos:

"2661. Dominio imperfecto es el derecho real revocable ó fiduciario de una sola persona sobre una cosa propia, mueble ó inmueble, ó el reservado por el dueño perfecto de una cosa que enajena solamente su dominio útil.

"2662. Dominio fiduciario es el que se adquiere en un fideicomiso singular, subordinado á durar solamente hasta el cumplimiento de una condición resolutiva, ó hasta el vencimiento de un plazo resolutivo, para el efecto de restituir la cosa á un tercero"

Parcimoniosamente, como se vê, cuidou o Código Civil argentino do domínio fiduciário, a que também se referiu seu art. 3730, para assentar que la nulidad de la sustitucion fideicomisaria no perjudica la validez de la institucion del heredero, ni los derechos del llamado antes.

Não obstante, sem dificuldade se nota o ponto predominante da instituição do fideicomisso; e vem a ser que, por via dêle, o fiduciário recebe em propriedade os bens a restituirem-se ao beneficiário da doação ou da cláusula testamentária.

Essa propriedade é o domínio imperfeito; mas é domínio, posto que restrito e limitado no tempo.

\section{O fideicomisso no Código Civil brasileiro}

Não com diverso caráter contemplou o fideicomisso o Código Civil brasileiro. 
No capitulo das substituições hereditárias, e não no da propriedade, êle o acolheu. Foi no art. 1733. Pode também o testador instituir herdeiros ou legatarios por meio de fideicomisso, impondo a um dêles - o gravado ou fiduciário, a obrigação de, por sua morte, a tempo certo, ou sob certa condição, transmitir ao outro - o fideicomissário, a herança ou o legado.

Advertiu no entretanto, no artigo subsequente, ter o fiduciário a propriedade da herança ou legado, mas restrita e resolúvel, de onde ser obrigado a proceder ao inventário dos bens gravados e, se lho exigir o fideicomissário, a prestar caução de restituí-los.

Essa propriedade, restrita e resolúvel, é conversível $\mathrm{em}$ propriedade plená. O fideicomissário pode renunciar à herança ou legado; e, neste caso, o fideicomisso caduca, ficando os bens proprielade pura do fiduciário, inexistindo disposição contrária do testador. Dí-lo o art. 1735. Ademais disso, qual reza o art. 1738, caduca o fideicomisso se o fideicomissário morrer antes do fiduciário, ou antes de realizar-se a condição resolutória dêste último. Neste caso, a propriedade se consolida no fiduciário, dês que o testador não tenha previsto o evênto, dando-lhe a solução convinhável.

De resto, e eis circunstância de monta, consignada no art. 1740 , a nulidade da substituição ilegal não prejudica a instituição, que valerá sem o encargo resolutório.

É o fiduciário senhor e possuidor dos bens que lhe são fideicometidos, de molde a poder usá-los e fruí-los livremente, nada se opondo até a que os aliene, de vez que sua propriedade é resolúvel. Verificada a condição resolutiva, os bens de pleno direito se transmitem ao fideicomissário, ainda que em poder de terceiros. Não é méro depositário dêles o fiduciário. Nem simples administrador provisório, investido de mandato, que sòmente pode cumprir no fideicomisso a tempo certo, ou sob certa condição, jamais no de sua morte. 
Registre-se, como nota histórica, que, nos trabalhos parlamentares da elaboração do Código Civil, se pretendeu suprimir o fideicomisso. Argumentou a Comissão do Senado Federal ter êle perdido terreno, de molde a ter sido banido de alguns códigos e admitido em outros mui restritamente.

"O fideicomisso", expôs a Comissão, "o fideicomisso não traz nenhuma vantagem, que não possa ser igualmente of erecida pelo usufruto, com a notável conveniência de ser êste mais simples, menos sujeito a ser frustrado, mais garantido e menos acessível às disputas dos interessados. O Código Civil ganha em desprender-se de coisas inúteis, que só têm por si o prestígio da tradição. O fideicomisso está neste caso: se o fiduciário puder dispôr dos bens, difícil coisa seria obter que o fideicomissário viesse a receber o equivalente; se não puder dispor, torna-se patente a identidade entre o fideicomisso e o usufruto. Tudo aconselha a banir do Código essa fonte de controvérsias e de fraudes, como procedeu o Código italiano. O usufruto preenche a função do fideicomisso, com mais segurança, sem os seus inconvenientes. É portanto natural que êste último ceda diante da superioridade do outro instituto, dando por terminada sua missão".

A palavra do Senado Federal não foi ouvida pela Câmara dos Deputados; e o fideicomisso logrou mantença no corpo do Código Civil e tem atendido a sua missão, sendo muito mais comuns, na prática, os fideicomissos do que os usufrutos.

Não fique sem referência entretanto que o Código Civil da Itália, de 1942, introduziu em seu contexto a substituição fideicomissária, dentro dos limites estabelecidos no art. 692:

"E valida la disposizione con la quale il testatore impone al proprio figlio l'obbligo di conservare e restituire 
alla sua morte in tutto o in parte $i$ beni constituenti la disponibile a favore di tutti i figli nati e nascituri dall'istituito o a favore di un ente pubblico.

"É valida ugualmente la disposizione che importa a' carico di un fratello o di una sorella del testatore l'obbligo. di conservare e restituire $i$ beni ad essi lasciati a favore dit tutti i figli nati e nascituri da essi o a favore di un ente pubblico.

"In ogni altro caso la sostituzione é nulla"

Quebrou-se com a hostilidade do legislador. Como observou, a propósito, Mảrio Rotond, a substituição fideicomissária invece ha trovato spesso ostile $i$ legislatori moderni, che ritennero economicamente e socialmente dannosi vincoli perduranti alla libera disponibilità dei beni (2).

As origens romanas do fideicomisso sucessório e a fiducia obrigacional

Com tais substância e objetivo, veio o fideicomisso, quer para as Sete Partidas, quer para as Ordenações Filipinas, espraiando-se nas legislações oriundas daqueles dois códigos, das fontes romanas.

Os vários tipos de legados confluídos no direito justinianêu padeceram a influência do fideicomisso, suaviza-dor das formas austeras do antigo direito hereditário. Surgido à ilharga do regime jurídico dos romanos, nele se infiltrou a fim de que os peregrinos e quantos não ti-vessem a testamenti factio passiva pudessem aquinhoar-se: com as liberalidades que sòmente se cometem por disposições de última vontade.

(2) Mário Rotond, Istituzioni di Diritto Privato, Milão, 1945 50 : ed. da Casa Editrice Ambrosiana, pág. 624, nº 317. 
Ao que referem as Institutas de Galo, havia grande diferença entre disposições por fideicomisso e diretamente por legado. Podia-se instituir fideicomisso por via do herdeiro do herdeiro, e não o legado: nam ecce fideicommissum etiam $a b$ herede heredis relinqui potest. Se legados feitos em codicilos só valiam quando confirmados pelos testadores, válidos eram os fideicomissos outorgados mesmo em codicilos não ratificados. Fideicommissum vero etiam non confirmatis codicillis relinqui potest. Se por nulos se tinham os legados escritos em grego, valiam entretanto os fideicomissos. Item legata Graece scripta non valent; fideicommissa vero valent.

De tanta importância se revestiu o fideicomisso, que não podia a lei deixar de dar-lhe guarida, garantindo-lhe a execução.

Não cabe, nesta assentada, a súmula histórica do fideimisso, de molde a salientar-lhe os momentos evolutivos. Modo de sucessão mortis causa, mesmo no direito de JusTINIANo, se aplicou tanto à successio per universitatem, como $\grave{a}$ in singulares. Acabou por confundir-se com os modos originários que as palavras hereditas e legatum exprimiam, a despeito de que o fideicomisso universal tivesse conservado particularidades que o tornavam característico, mesmo no direito novo e, por isso, distinto, sob certos aspectos, da herança ordinária ou direta.

Diga-se no entanto, de passagem, acompanhando a exposição de Maynz, que, como o herdeiro encarregado de entregar a herança podia realmente executar a vontade do defunto, fazendo a tradição das coisas corpóreas e a cessão dos créditos; mas como esta maneira de agir era assaz complicada, se recorreu a processo mais simples, operando a transferência por meio de venda imaginária. Foi essa quiçá primeira fórmula do que hoje se tem como negócio fiduciário. Vendia o fiduciário pro forma a herança ao fideicomissário; e, para a segurança de seus direitos e obrigações recíprocos, se estipulavam as garantias usuais nas vendas de heranças. Mas tudo isso era relativo. $O$ fidu- 
ciário era sempre o titular dos direitos e obrigações do defunto, expondo-se às consequências prejudiciais dessa obrigação e podendo, de resto, abusar em prejuizo do fideicomissário. Tiveram fim êsses inconvenientes com o senatusconsulto Trebeliano, anterior de um ano ao Neroniano, estabelecendo que, após à restituição da herança, tôdas as ações hereditárias pertenciam de pleno direito como ações úteis ao fideicomissário, sujeitando-se por isso mesmo às ações dos credores. O fiduciário não poderia mais ser acionado como dono da herança e dispunha da exceptio restitutae hereditatis (3).

Sem embargo, era possivel que o fiduciário, não tendo interêsse em adquirir a herança, que seria obrigado a restituir, a ela renunciasse, ensejando a caducidade do fideicomisso. Para obviar essa dificuldade, que inutilizava o instituto, o senatusconsulto Pegasiano autorizou o fiduciário, que aceitasse a herança, que lhe era fideicometida, do mesmo modo que no legado, retivesse, ao restituir os bens, a quarta da lei Falcídia, o que se refletiu, como já se observou, na lei das Sete Partidas.

Evolveu o instituto do fideicomisso até adquirir a estrutura com que se apresentou nas leis modernas, que atribuiram ao fiduciário a propriedade da herança de molde a interessá-lo nela, para seu uso e gôzo até ao evento resolutivo de seu domínio, com a transferência dêste de pleno direito ao fideicomissário.

o mesmo princípio, que orientou o fideicomisso, na parte hereditária, fomentou, na contratual, a fidúcia, que logrou vasta aplicação e interêsse imenso no direito clássico. Deixa, bem o disse Bonfante, por sua estrutura, incluir-se entre os contratos reais, e pode ser que assim tivesse sido; mas aboliu-se no direito justinianeu. Era a convenção por que uma das partes - o fiduciário, recebendo de outra - o fiduciante, uma coisa, pela forma da - man-

(3) Charles Maynz, Cours de Droit Romain, Paris-Bruxelds, 1874 , t. III, $3^{\circ}$ ed. A Durand-Pedone, pág. 662, § 527. 
cipatio ou jure in cessio, se obrigava a usá-la para fim determinado, e, em regra, restituí-la, exaurido aquêle fim.

Era a fidúcia de natureza vária. Prestava-se para concessão ao credor de garantia real; e tinha-se o pignus iure cum creditoris. Ajustava-se dando a coisa em depósito ou a comodato, isto é, em gôzo gratuito, ou para qualquer outro uso. Daí a grande utilidade do contrato (4). Teve aplicações múltiplas; e, em direito de família, se aplicou em caso de emancipação, de adoção, coemptio, reemancipação em consequência do divórcio.

Contraía-se a fidúcia com mais frequência para soluções obrigacionais, qual decorre das Institutas de GaIo, 2, 60 , ou com credor, ou com amigo, que guardasse os bens mais seguramente. Contraída com amigo, cabia sempre a usurrecepção. Contraída com credor, sempre que o devedor lhe não alugasse a coisa ou não lhe desse a posse a título precário, cabia então o usucapião lucrativo. Sed cum fiducia contrahitur aut cum creditore pignoris jure aut cum amico, quo tutius nostrae res apud eum essent, siquidem cum amico contracta sit fiducia, sane omni modo competit usureceptio: si vero cum creditore, soluta quidem pecunia omni modo competit, nondum vero soluta ita demum competit, si neque conduxerit eam rem a creditore debitor, neque precario rogaverit, ut eam rem obligatum possidere liceret: quo casu lucrativa ususcapio competit.

\section{A "Treuhand" germânica e o "trust" anglo-saxão}

As mesmas necessidades criam normas e institutos jurídicos em diversos povos, apresentando característicos fundamentais idênticos, ao lado de peculiaridades locais.

Se, em Roma, surdiram o fideicomisso e a fidúcia, tendo como elemento comum a interferência de pessoa mere-

(4) Pietro.: Bonfante; Istituzioni di Diritto * Romano, : Turim, 1946, ed. G. Giapicchelli, pág. 471, § 157. 
cedora de confiança para a efetividade de negócios írrealizáveis, no momento, diretamente; demasia não havia de ser que os germanos, por criação própria, ou por influência do Direito Romano, criassem os chamados negócios fiduciários, nas diversas modalidades.

Destaca-se entre êsses a instituição da Treuhand, fundada no elemento comum da fides, confiança, ou Treu, que se tem ligado à fiducia romana. Nesta instituição germânica, o Treugeber entrega ao Treuhänder certa coisa, chamada Treugut. Nesse negócio, adquire o Treuhänder direito de natureza real, mas diferente do de propriedade, como quando se entrega a coisa com reserva de domínio, que subsiste no Treugeber e lhe permite retomar o Treugut em mãos do Treuhänder, ou de terceiro, por via de ação real.

Esta instituição, ao que refere Cladde Reymond, advém da do Salmann, que representa, no direito germânico, papel análogo ao do testamenteiro ou do tutor, em direito moderno. Tem êle direito próprio e de natureza real na administração Salgut: o beneficiário dessa administração (herdeiro ou tutelado) igualmente dispõe de direito real sôbre o mesmo bem.

o Direito Romano, na advertência do monografista suiço, se recusa a admitir a divisão da propriedade em vários direitos distintos. Nisso diverge do Direito germânico. Compreende-se pois que reminiscências românicas houvessem inspirado os juristas alemães quando tentaram obter os efeitos da Treuhand em sistema jurídico romanizado (5).

Por igual se tem admitido que da fidúcia romana se originou o instituto anglo-americano do trust, que se há conceituado como a relação jurídica que nasce quando uma pessoa, chamada - trustee, se obriga, pela equity, a exercer

(5) Claude Reymond, Essai sur la nature et les limites de l'acte fiduciaire, Montreux, 1948, Imprimerie Ganguin et Laubscher, S. A., pág. 5, no 3; Mariano Navarro Martorelli, La Propiedad Fiduciaria, Barcelona, 1950, Casa Editorial Bosch, pág. 40. 
seus direitos em proveito de outras pessoas, que são cestui que trust, ou para permitir que se logre fim certo, de tal sorte os lucros pertençam, não ao trustee, mas ao beneficiário, ou dono do negócio - o settlor,

Visto o trust por êsse ângulo, pode-se, sem receio de erronia, avançar que o exemplo mais preciso dêle é o contrato de comissão mercantil. Este é, no direito brasileiro, o contrato por via do qual o comissário, como comerciante que é, recebe de seu comitente, coisas, gêneros ou produtos a fim de vender, como se seus próprios fôssem, revertendo os lucros em benefício dêste. Entra, nesse contrato, como elemento fundamental, a confiança. Por via desta, entrega o comitente, seja outro comerciante, seja o agricultor, seja o industrial, ao comissário, bens negociáveis, por êste recebidos e desde então havidos como seus, sem que, refere o art. 165 do Código Comercial, "nesta gestão seja necessário declarar ou mencionar o nome do comitente"

O trust, e valha a ensinamento de Phanor J. Eder, é resultado de método ideiado pelos advogados a fim de iludir o Statute of Uses (lei de usos), sancionada em 1535, sôbre bens imóveis, e que foi o principal fundamento da transmissão da propriedade na Inglaterra até às reformas de 1925. O trust primitivo do direito inglês em verdade pode ter sido sugerido pela instituição romana do fideicommissum ou da fiducia; mas se originou naturalmente e desde logo deixou de ser meio de aplicação do Statute of Uses, das leis de mãos mortas e outras semelhantes, para converter-se em instrumento de arranjos familiares e, mais adiante, na coluna vertebral dos negócios, mercê de sua extraordinária flexibilidade e adaptabilidade, tanto em situações simples, como nas complexas (6).

Assim entendem uns (Story, Geldart, Stephen, SalMONd, Roscoe Pound e outros); mas não poucos (Maitland,

(6) Roberto Goldschmidt \& Phanor J. Eder, El fideicomiso ("trust") en derecho comparado (especialmente americano), Buenos Aires, 1954, Ediciones Aray, pág. 29. 
Under Hill, Langdel, Harlan F. Stone e outros) sustentam que o cestui que trust não ostenta verdadeiro direito de propriedade, mas direito pessoal sôbre o trustee (7).

Como no fideicomisso de cêpa romana o fiduciário adquire a propriedade da coisa e, por igual, na fidúcia, se tem buscado nesses velhos institutos do Direito Romano os característicos do trust inglês.

\section{O transplantio do "trast" para as legislações americanas}

Descobriu o comércio inglês, muito antes do comércio norte-americano, as praças consumidoras da América latina. Entrando a negociar nos países de língua espanhola, como no de língua lusitana, os inglêses, como é de imaginar, foram logo introduzindo nelas os seus métodos e usos comerciais. Para maior garantia de seus negócios, neles criaram filiais de seus grandes bancos e disputaram os grandes empreendimentos nacionais, como as construções das primeiras linhas ferroviárias. Organizaram-se para isso sociedades anônimas, que houveram de lançar empréstimos a prazos longos nas praças em que operavam, emitindo-se debentures lançadas no país e em Londres, aparecendo então em cena os primeiros trustees, como representantes dos debenturistas inglêses.

Trust, trustee, settlor e outros têrmos peculiares ao comércio britânico, intraduziveis em espanhol ou em português, entraram no uso do comércio local e quem os empregava sabia bem a moeda que tinha na mão.

o primeiro país americano que, salvo êrro, legislando sôbre a emissão de títulos ao portador lançados por sociedades anônimas, tomou a si o enquadramento, em seu sistema, dos trustees, foi a Argentina, pela lei n. ${ }^{\circ} 8875$, de 1912, que substituiu os arts. 365 a 368 do seu Código do Comércio.

(7) Mariano Navarro Martorelli, La Propriedad Fiduciária, Barcelona, 1950, Casa Editorial Bosch, pág. 206. 
Estabeleceu aquela lei, em seu art. 3, que quem tomasse a iniciativa de emitir debentures, deveria celebrar um contrato com um ou vários representantes dos futuros tomadores de tais títulos, que se chamariam - fideicomisários, contrato no qual se estipulariam as condições do empréstimo e as garantias que se outorgariam a favor dos mutuários e mais cláusula convinháveis. Eiss no que se equivocou o legislador argentino quanto à terminologia. Fideicomisario dicese de la persona a quien se destina un fideicomiso e nao o heredero o legatario a quien el testador manda trasmitìr los bienes a otra $u$ otra personas, o darles determinada inversión. Este é o fiduciario, que depende del crédito y confianza que merezca.

Ora, assim como na instituição fideicomissária os a que o fideicomisso se destina são os fideicomissários, no lançamento do empréstimo debenturístico os a que os títulos se destinam, usando da mesma terminologia, seriam como que os fideicomissários. Fiduciários se devem reputar, portanto, os intermediários entre os fideicomitentes e os fideicomissários.

Foi no que variou a terminologia argentina, que houve os fideicomissários como los representantes de los tomadores de debentures, acrescentando todavia que sus deberes se regirán por las reglas del mandato. O que parece incompreensivel, de verdade, é a existência de fideicomisso sem a figura do fiduciário, que representa papel de extraordinária importância.

É possível (e bem pode ser que a versão seja inteiramente desarrazoada) que dessa iniciativa da lei argentina tenha resultado chamar-se - de fideicomiso o que, em geral, nas leis de alguns países americanos de fala castelhana, se tem havido como substitutivo, ou ad instar, do trust de origem anglo-saxônica.

Com exatitude, neste particular, dispôs o Código Civil de Pôrto Rico, no art. 834, que el fideicomiso es un mandato irrevocable a virtud del cual se trasmiten determinados bienes a una persona, llamada fiduciário, para que dis- 
ponga de ellos conforme lo ordene la que los trasmite, llamada fideicomitente, a beneficio de este mismo o de un tercero llamado fideicomisario.

Não diverge, neste ponto, a lei de 1941 do Panamá; mas a lei de 1923 da Colômbia, permitindo aos estabelecimentos bancários a criação de uma sección fiduciaria, entende por fideicomiso todo encargo de confianza de los en ella expresados, y por fideicomisario el individuo o entidad a quien se encomienda el encargo.

Já a lei 608, de 11 de julho de 1929, da Bolívia, permite aos bancos comerciais e hipotecários establecer y operar secciones de fideicomiso.

A lei geral de bancos do Chile, promulgada pelo decreto-lei n. 559, de 26 de setembro de 1925, como as reformas introduzidas pelo Decreto-lei n. 782, de 21 de dezembro de 1935, tornou possivel autorizar a los bancos comerciales para que obren como secuestres, depositários, mandatários, administradores de bienes ajenos y para que desempeñen cualqueira otra función de confiança que las leyes permitan conferir; e a lei n. 4827, de 17 de fevereiro de 1930, estabeleceu quais os atos que constituem comisiones de confianza.

Também a lei de bancos, 7.159, de 23 de maio de 1931, permitiu que os bancos comerciais constituídos de conformidade com ela, e as sucursais dos bancos comerciais estrangeiros autorizados a operar naquele país, que aceitem e cumpram comisiones de confianza.

De qualquer modo, os bancos, mercê de tais diplomas legislativos, tratando-se de fideicomisos ou de comisiones de confianza, sejam fiduciários, sejam fideicomisarios, operam como mandatários, em alguns países com mandato irrevogável.

Este é o punctum saliens, o ponto de partida para o estabelecimento da natureza jurídica do fideicomiso, pelo menos na ordem bancária. 
Os rumos do problema na doutrina e na jurisprudência do Brasil

No Brasil, não escapou o problema do trust ao exame dos doutrinadores.

“Há”, escreveu J. X. Carvalho de Mendonça, "há uma figura jurídica, que se vai aceitando com vantagem no Direito Comercial, o negócio fiduciário. Os contratantes, para conseguirem determinado fim prático, com as consequências de direito, ajustam que um figure nas relações para com terceiros como proprietário de uma coisa ou credor de um crédito que ao outro pertence. Nas relações internas, entre o depositário da confiança, chamado por isso fiduciário, e o proprietário da coisa, ou credor da obrigação, existe simples mandato. Se o fiduciário abusa da confiança que se lhe depositou, apropriando-se do que the fôra entregue, comete o crime de furto, sendo entretanto sempre válidos relativamente a terceiros os atos de disposição. Se o fiduciário falir, o mandante pode reivindicar da massa falida os bens fiducialmente entregues. $O$ negócio fiduciário não é um ato simulado, mas um negócio sério, realmente concluído pelos contratantes, para obterem, como dissemos, efeitos práticos para fins econômicos. Exemplos dêsses negócios: a transmissã̃o da propriedade de uma coisa ou de títulos de crédito com o escopo de penhor, a cessão de um crédito para o fim de efetuar a cobrança, etc." (8).

Praticam-se, em verdade, contratos inúmeros com estabelecimentos bancários, ou com comerciantes ou capitalistas, que se poderiam reputar congêneres do trust. Mas ainda não se sentiu a necessidade de dar carta de cidadania brasileira a êsse instituto anglo-saxão. Não se sentiu essa

(8) J. X. Carvalho de Mendonça, Tratado de Direito Comercial Brasileiro, Rio de Janeiro, 1917, voi. VIII, Tip. Besnard Frères, pág. 280 , n. 994.

(9) Arquivo Juditiciário, Rio de Janeiro, 1931, vol. XVI, pág. 131. 
necessidade porque tais contratos, sejam quais forem os nomes por que se batisem, se resolverão pelas regras da comissão mercantil, quando haja a entrega da coisa a ser negociada, ou do mandato.

Disso não há fugir; e os exemplos, agora examinados, dos fideicomisos de diversos países americanos, demonstra cabalmente que diferentemente não pode ser, tanto que todos êles divisaram, na essência daquelas figuras contratuais, o mandato, irrevogável ou não.

Também no Brasil êsse mandato pode ser irrevogável. Depende da natureza das coisas. Pelo que preceitua o art. 1317, II, do Código Civil, é irrevogável o mandato, "nos casos, em geral, em que fôr condição de um contrato bilateral ou meio de cumprir uma obrigação contratada, como è, nas letras e ordens, o mandato de pagá-las".

Já foi, de resto, decidido pela Côrte de Apelação do Distrito Federal, em acórdão de 12 de agôsto de 1930, que, "efetivamente o instituto do trust, ou o negócio fiduciário. assenta em uma relação de mandato, que é simples entre o beneficiário e o trustee, e entre êste e terceiros, por isso mesmo que êle age como dominus e proprietário formal ou aparente, como se o negócio fôra próprio; a sua posição é ainda de mandatário, configurada nos casos dos arts. 1307, do Código Civil ou 150 do Código Comercial, ou porque o mandato assuma a modalidade da comissão, tratando-se de operação mercantil, a de comissário, que contrata em seu nome próprio (Cod. Com., art. 166). Nessa posição, detém a coisa conferida pelo mandante, com a obrigação de guardá-la, enquanto não lhe fôr dado o destino prefixado, como depositário" 